\title{
Mass Spectra of Some Deuterostyrenes
}

\author{
Edith I. Quinn and Fred L. Mohler
}

\begin{abstract}
Mass spectra of alpha, beta, and para deuterostyrene; beta, beta dideuterostyrene; and alpha, beta, beta trideuterostyrene have been measured. The spectra are compared with the intensity distribution computed on the assumption of a random distribution of deuterium in $\mathrm{C}_{8} \mathrm{H}_{8}$. This gives a fair approximation to the observed spectra. The spectra of doubly chrrged styrenes are computed on the basis of observed half integer peaks in $\mathrm{C}_{8} \mathrm{H}_{8}$ and $\mathrm{C}_{8} \mathrm{H}_{7} \mathrm{D}$. The metastable transition peaks of the deuterostyrenes have been recorded. It is suggested that ionized styrene molecules may form an octatetraene ring which dissociates with a random distribution of deuterium atoms but the observed spectra are not completely random and there may be other modes of fragmentation.
\end{abstract}

\section{Introduction}

The study of mass spectra of deuterium substituted hydrocarbons has been a rewarding field of research, for the distribution of deuterium atoms among the fragment ions gives information on the mechanism of jonization. The results have in many instances been unexpected and interesting. In simple paraffinic hydrocarbons the distribution of deuterium atoms in fragment ions seems to correspond to the structure of the molecule. This is the case in deuterium substituted butanes [1] ${ }^{1}$. In other types of deuterated hydrocarbons there is more or less rearrangement of hydrogenic atoms in the ionization process and this is strikingly shown in aromatic hydrocarbons [2].

Five deuterium substituted molecules have been synthesized by Leo A. Wall [3] of the Polymer Structure Section. These were alpha, beta, and para deuterostyrene; beta, beta-dideuterostyrene; and alpha, beta, beta-trideuterostyrene. These styrenes were made over a period of years and the mass spectra were published in the American Petroleum Institute (API) catalog of mass spectrai data [4]. It has seemed worthwhile to repeat the measurements under uniform conditions and present the results in a format convenient for intercomparison of results.

\section{Experimental Procedure and Results}

Measurements were made with a $180^{\circ}$ Consolidated model 21-103 mass spectrometer under standard conditions of operation. Mass spectra reported in table 1 were recorded with a metastable suppressor set with an intermediate retarding field. Spectra were also recorded with the suppressor off to record the metastable transition peaks.

The deuterostyrenes were of good chemical purity and air was the only appreciable impurity. The isotopic purity was measured at low voltage to make the molecule ion predominant. The isotopic impurities ranged from 1 to 4 percent and were consistent with values given in the API catalog of mass spectra [4] except that the beta deuterostyrene was

\footnotetext{
${ }_{1}^{1}$ Figures in brackets indicate the literature references at the end of this paper.
}

a much better sample than before. It contained about 4 percent of styrene.

Table 1 lists the singly charged ions of stvrene and the five deuterostyrenes. The observed relative intensities have been corrected for the contribution of $\mathrm{C}^{13}$ isotopes, and for chemical and isotopic impurities. The 51,52 , and 53 peaks have been corrected for doubly charged ions on the basis of data in table 3. The corrections for chemical impurities may be subject to appreciable error. Peaks in the mass range 12 to 30 are small, and small inaccuracies in the air correction may explain some irregularities in relative intensities of peaks at masses 14 and 28 .

Data of table 1 show that the mass spectra of the three monodeutero styrenes are similar and there is no close correlation between the position of deuterium in the molecule and the resulting spectrum. This suggests that there is a nearly random distribution of hydrogenic atoms in the fragment ions. Thus it is of interest to compare the observed spectra with spectra that would result from random removal of $\mathrm{H}$ and $\mathrm{D}$ atoms from $\mathrm{C}_{8} \mathrm{H}_{7} \mathrm{D}, \mathrm{C}_{8} \mathrm{H}_{6} \mathrm{D}_{2}$, and $\mathrm{C}_{8} \mathrm{H}_{5} \mathrm{D}_{3}$.

Table 2 indicates how the computation is made for $\mathrm{C}_{8} \mathrm{H}_{7} \mathrm{D}$. The numbers in parentheses denote the intensity of peaks in the $\mathrm{C}_{8} \mathrm{H}_{8}$ spectrum. Two different ions contribute to most of the peaks. The number of carbon atoms in the fragments does not enter into the computation, so the same relations hold for ions with 1 to 7 carbon atoms. In dideutero and trideutero styrene three different ions contribute to many of the peaks and the computations require more entries.

In table 1 columns 3, 7, and 9 headed "Computed $\mathrm{C}_{8} \mathrm{H}_{7} \mathrm{D}$ ", etc., give these values computed from the $\mathrm{C}_{8} \mathrm{H}_{8}$ spectrum. It will be seen that in general the observed spectra are much like the spectra computed for a random distribution of $\mathrm{D}$ atoms in the fragment ions, although the agreement is far from exact.

\subsection{Multiply Charged Ions}

The API tables of styrene spectra [4] show half integer peaks in the mass range 25.5 to 53.5. These come from doubly charged ions of odd mass number. Table 3 lists the observed mass peaks at half integer mass numbers in the mass range 48.5 to 53.5. The other half integer peaks are very small and have been 
TABLE 1. Mass spectra of styrene and deuterostyrenes a

\begin{tabular}{|c|c|c|c|c|c|c|c|c|c|}
\hline$m / e$ & $\mathrm{C}_{8} \mathrm{H}_{8}$ & $\begin{array}{c}\text { Computed } \\
\mathrm{C}_{8} \mathrm{H}_{7} \mathrm{D}\end{array}$ & $\begin{array}{c}\alpha-d- \\
\text { styrene }\end{array}$ & $\begin{array}{c}\beta-d- \\
\text { styrene }\end{array}$ & $\begin{array}{c}p, d- \\
\text { styrene }\end{array}$ & $\begin{array}{c}\text { Computed } \\
\mathrm{C}_{8} \mathrm{H}_{6} \mathrm{D}_{2}\end{array}$ & $\begin{array}{l}\beta \beta-d_{2^{-}} \\
\text {styrene }\end{array}$ & $\underset{\mathrm{C}_{8} \mathrm{H}_{5} \mathrm{D}_{3}}{\text { Computed }}$ & $\begin{array}{l}\alpha-\beta, \beta-d_{3} \\
\text { styrene }\end{array}$ \\
\hline $\begin{array}{l}12 \\
13 \\
14 \\
15 \\
16 \\
17 \\
18\end{array}$ & \begin{tabular}{c}
0.27 \\
.30 \\
.26 \\
.92 \\
\hdashline$-\cdot-\cdot$ \\
.---
\end{tabular} & $\begin{array}{r}0.27 \\
.26 \\
.23 \\
.64 \\
.35 \\
\\
\end{array}$ & $\begin{array}{r}0.15 \\
.16 \\
.36 \\
.37 \\
.24 \\
\end{array}$ & 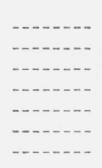 & $\begin{array}{r}0.22 \\
.27 \\
.23 \\
.72 \\
.14 \\
- \\
\end{array}$ & $\begin{array}{r}0.27 \\
.22 \\
.22 \\
.45 \\
.52 \\
.21 \\
\end{array}$ & $\begin{array}{r}0.11 \\
.06 \\
.38 \\
.47 \\
.22\end{array}$ & $\begin{array}{l}0.27 \\
.19 \\
.20 \\
.29 \\
.52 \\
.50 \\
.02\end{array}$ & $\begin{array}{l}0.07 \\
.21 \\
.23 \\
.21 \\
.14\end{array}$ \\
\hline $\begin{array}{l}24 \\
25 \\
26 \\
27 \\
28 \\
29 \\
30 \\
31\end{array}$ & $\begin{array}{r}.09 \\
.54 \\
4.54 \\
8.19 \\
1.13 \\
-.- \\
-0-\end{array}$ & $\begin{array}{r}.09 \\
.47 \\
3.47 \\
6.65 \\
3.63 \\
0.56 \\
- \\
-.--\end{array}$ & $\begin{array}{r}.06 \\
.24 \\
2.13 \\
4.08 \\
4.46 \\
0.09 \\
--.--\end{array}$ & $\begin{array}{l}0.04 \\
.15 \\
1.24 \\
2.17 \\
5.85 \\
0.07 \\
- \\
-\end{array}$ & $\begin{array}{r}.09 \\
.49 \\
3.39 \\
6.24 \\
1.99 \\
0.45 \\
-\cdot-\cdot \\
-\end{array}$ & $\begin{array}{r}.09 \\
.41 \\
2.57 \\
4.86 \\
4.78 \\
1.52 \\
0.24 \\
--.-\end{array}$ & $\begin{array}{r}.07 \\
.28 \\
1.95 \\
3.48 \\
1.68 \\
2.86 \\
0.09 \\
-\end{array}$ & $\begin{array}{r}.09 \\
.34 \\
1.82 \\
3.89 \\
4.95 \\
2.67 \\
0.62 \\
.08\end{array}$ & $\begin{array}{l}.08 \\
.28 \\
1.92 \\
2.66 \\
4.10 \\
1.56 \\
2.80 \\
0.09\end{array}$ \\
\hline $\begin{array}{l}36 \\
37 \\
38 \\
39 \\
40 \\
41 \\
42 \\
43 \\
44\end{array}$ & \begin{tabular}{r}
0.30 \\
2.98 \\
4.42 \\
11.40 \\
0.19 \\
.27 \\
\hdashline- \\
.---
\end{tabular} & $\begin{array}{r}.30 \\
2.61 \\
3.69 \\
8.22 \\
4.31 \\
0.20 \\
.17 \\
-.-\end{array}$ & $\begin{array}{r}.26 \\
2.24 \\
3.29 \\
7.91 \\
4.02 \\
0.18 \\
.18 \\
- \\
-\end{array}$ & $\begin{array}{r}.23 \\
1.95 \\
2.81 \\
6.52 \\
2.88 \\
0.18 \\
.14 \\
\hdashline\end{array}$ & $\begin{array}{r}.30 \\
2.28 \\
2.91 \\
7.76 \\
4.92 \\
0.84 \\
.28 \\
\end{array}$ & $\begin{array}{l}.30 \\
2.24 \\
3.11 \\
5.97 \\
6.30 \\
1.36 \\
0.18 \\
.10 \\
.04\end{array}$ & $\begin{array}{r}.27 \\
2.13 \\
3.14 \\
6.52 \\
3.70 \\
2.02 \\
0.16 \\
.36 \\
.06\end{array}$ & $\begin{array}{r}.30 \\
1.86 \\
2.70 \\
4.40 \\
6.58 \\
3.13 \\
0.35 \\
.15 \\
.05\end{array}$ & $\begin{array}{r}.28 \\
1.86 \\
2.88 \\
5.36 \\
4.08 \\
2.77 \\
1.06 \\
0.24 \\
.12\end{array}$ \\
\hline $\begin{array}{l}48 \\
49 \\
50 \\
51 \\
52 \\
53 \\
54 \\
55 \\
56 \\
57\end{array}$ & $\begin{array}{c}.15 \\
2.10 \\
16.8 \\
24.4 \\
6.20 \\
1.03 \\
0.14 \\
.01 \\
-.-\end{array}$ & $\begin{array}{c}.15 \\
1.84 \\
12.8 \\
19.5 \\
12.3 \\
3.49 \\
0.68 \\
.11 \\
-\cdot--\end{array}$ & $\begin{array}{c}.13 \\
1.53 \\
12.1 \\
17.5 \\
9.45 \\
3.11 \\
0.70 \\
.10 \\
\end{array}$ & \begin{tabular}{c}
.14 \\
1.54 \\
11.3 \\
15.9 \\
7.69 \\
3.05 \\
0.79 \\
.10 \\
\hdashline \\
.--
\end{tabular} & $\begin{array}{c}.15 \\
1.52 \\
10.1 \\
15.2 \\
12.5 \\
4.40 \\
0.68 \\
.23 \\
\\
\end{array}$ & $\begin{array}{r}.15 \\
1.58 \\
9.51 \\
15.9 \\
15.1 \\
6.16 \\
1.88 \\
0.43 \\
.07\end{array}$ & $\begin{array}{r}.14 \\
1.34 \\
9.65 \\
15.0 \\
8.66 \\
5.23 \\
1.96 \\
0.64 \\
.09 \\
-. .-\end{array}$ & $\begin{array}{c}.15 \\
1.31 \\
6.78 \\
13.4 \\
16.7 \\
9.25 \\
3.38 \\
1.00 \\
0.25 \\
.05\end{array}$ & $\begin{array}{c}.14 \\
1.16 \\
8.18 \\
13.8 \\
8.9 \\
6.58 \\
2.41 \\
1.60 \\
0.41 \\
.15\end{array}$ \\
\hline $\begin{array}{l}60 \\
61 \\
62 \\
63 \\
64 \\
65 \\
66 \\
67 \\
68 \\
69\end{array}$ & $\begin{array}{l}.29 \\
1.94 \\
3.37 \\
7.85 \\
0.59 \\
1.78 \\
0.10 \\
\\
\end{array}$ & $\begin{array}{r}.29 \\
1.70 \\
2.77 \\
5.75 \\
3.24 \\
0.97 \\
1.13 \\
0.08 \\
-\cdot-.-\end{array}$ & $\begin{array}{l}.23 \\
1.33 \\
2.35 \\
5.25 \\
3.08 \\
0.99 \\
1.01 \\
0.04 \\
\end{array}$ & $\begin{array}{r}.25 \\
1.43 \\
2.43 \\
5.14 \\
2.80 \\
1.03 \\
0.93 \\
.03 \\
\hdashline\end{array}$ & $\begin{array}{r}.26 \\
1.44 \\
2.44 \\
4.96 \\
3.53 \\
0.89 \\
1.04 \\
0.05 \\
-\end{array}$ & $\begin{array}{r}.26 \\
1.46 \\
2.28 \\
4.24 \\
4.45 \\
1.37 \\
1.08 \\
0.68 \\
.06\end{array}$ & $\begin{array}{r}.26 \\
1.27 \\
2.14 \\
4.43 \\
2.73 \\
1.83 \\
0.76 \\
.69 \\
.02\end{array}$ & $\begin{array}{r}.29 \\
1.21 \\
1.92 \\
3.20 \\
4.60 \\
2.38 \\
0.87 \\
1.00 \\
0.37 \\
.04\end{array}$ & $\begin{array}{l}.24 \\
1.02 \\
1.82 \\
3.62 \\
3.17 \\
2.37 \\
0.95 \\
.71 \\
.50 \\
.02\end{array}$ \\
\hline $\begin{array}{l}72 \\
73 \\
74 \\
75 \\
76 \\
77 \\
78 \\
79 \\
80 \\
81 \\
82\end{array}$ & \begin{tabular}{c}
.09 \\
1.30 \\
6.47 \\
4.02 \\
4.38 \\
20.8 \\
38.2 \\
0.43 \\
\hdashline$-\cdot-$ \\
.--
\end{tabular} & \begin{tabular}{c}
.09 \\
1.14 \\
5.01 \\
4.13 \\
3.70 \\
9.98 \\
22.5 \\
28.7 \\
0.38 \\
\hdashline$-\cdot-$
\end{tabular} & $\begin{array}{c}.08 \\
1.04 \\
4.37 \\
3.53 \\
3.24 \\
9.89 \\
22.1 \\
21.6 \\
0.07 \\
\end{array}$ & $\begin{array}{c}.09 \\
.96 \\
4.32 \\
3.50 \\
3.27 \\
9.57 \\
23.1 \\
20.7 \\
0.04 \\
\end{array}$ & $\begin{array}{c}.11 \\
1.21 \\
3.78 \\
4.02 \\
3.31 \\
7.40 \\
19.8 \\
29.4 \\
0.25 \\
\end{array}$ & $\begin{array}{c}.09 \\
.98 \\
3.68 \\
4.21 \\
3.32 \\
5.15 \\
13.4 \\
23.8 \\
20.6 \\
0.32 \\
-\end{array}$ & $\begin{array}{c}.08 \\
.80 \\
3.39 \\
3.41 \\
2.75 \\
5.83 \\
14.1 \\
21.6 \\
12.8 \\
0.06\end{array}$ & $\begin{array}{r}.09 \\
.81 \\
2.80 \\
4.18 \\
3.15 \\
3.33 \\
7.51 \\
15.5 \\
24.2 \\
13.8 \\
0.27\end{array}$ & $\begin{array}{c}.08 \\
.76 \\
2.79 \\
3.11 \\
2.35 \\
3.84 \\
6.84 \\
18.7 \\
17.0 \\
8.68 \\
0.04\end{array}$ \\
\hline $\begin{array}{l}84 \\
85 \\
86 \\
87 \\
88 \\
89 \\
90 \\
91 \\
92 \\
93 \\
94\end{array}$ & $\begin{array}{r}.09 \\
.27 \\
.42 \\
.06 \\
.06 \\
2.25 \\
0.02 \\
.37 \\
\\
\\
\end{array}$ & $\begin{array}{r}.09 \\
.24 \\
.35 \\
.54 \\
.30 \\
.87 \\
1.41 \\
0.07 \\
.32 \\
\end{array}$ & $\begin{array}{r}.08 \\
.17 \\
.29 \\
.50 \\
.26 \\
1.02 \\
1.08 \\
0.05 \\
.03 \\
\end{array}$ & $\begin{array}{r}.08 \\
.18 \\
.31 \\
.48 \\
.23 \\
1.23 \\
0.86 \\
.32 \\
.05 \\
\end{array}$ & $\begin{array}{r}.10 \\
.18 \\
.27 \\
.47 \\
.33 \\
.48 \\
1.64 \\
0.03 \\
.42 \\
\end{array}$ & $\begin{array}{r}.09 \\
.20 \\
.29 \\
.43 \\
.40 \\
.34 \\
1.21 \\
0.81 \\
.10 \\
.28 \\
\end{array}$ & $\begin{array}{r}.08 \\
.21 \\
.33 \\
.38 \\
.28 \\
.92 \\
.89 \\
.72 \\
.03 \\
.01 \\
\end{array}$ & $\begin{array}{r}.09 \\
.17 \\
.25 \\
.34 \\
.61 \\
.25 \\
.63 \\
1.20 \\
0.41 \\
.15 \\
.23\end{array}$ & $\begin{array}{l}.09 \\
.15 \\
.27 \\
.36 \\
.31 \\
.35 \\
.94 \\
.66 \\
.27 \\
.18 \\
.01\end{array}$ \\
\hline $\begin{array}{r}96 \\
97 \\
98 \\
99 \\
100 \\
101 \\
102 \\
103 \\
104 \\
105 \\
106 \\
107\end{array}$ & $\begin{array}{c}.02 \\
.24 \\
.89 \\
.18 \\
.05 \\
.95 \\
7.35 \\
45.1 \\
100 \\
\\
\\
\end{array}$ & $\begin{array}{c}.02 \\
.21 \\
.70 \\
.33 \\
.09 \\
.38 \\
2.43 \\
11.2 \\
39.5 \\
100 \\
\end{array}$ & $\begin{array}{c}.03 \\
.15 \\
.54 \\
.30 \\
.08 \\
.31 \\
2.15 \\
9.43 \\
36.6 \\
100 \\
\end{array}$ & $\begin{array}{r}.02 \\
.16 \\
.51 \\
.35 \\
.08 \\
.27 \\
1.99 \\
9.55 \\
40.0 \\
100 \\
-.--\end{array}$ & $\begin{array}{r}.03 \\
.14 \\
.50 \\
.36 \\
.08 \\
.27 \\
1.38 \\
8.76 \\
38.1 \\
100 \\
\end{array}$ & $\begin{array}{c}.02 \\
.18 \\
.54 \\
.44 \\
.14 \\
.15 \\
.78 \\
3.49 \\
15.2 \\
33.9 \\
100\end{array}$ & $\begin{array}{c}.04 \\
.11 \\
.33 \\
.42 \\
.13 \\
.11 \\
.62 \\
2.92 \\
13.0 \\
36.6 \\
100\end{array}$ & $\begin{array}{r}.02 \\
.15 \\
.41 \\
.51 \\
.20 \\
.09 \\
.27 \\
1.29 \\
4.11 \\
19.6 \\
28.2 \\
100\end{array}$ & $\begin{array}{r}.02 \\
.08 \\
.22 \\
.38 \\
.15 \\
.08 \\
.24 \\
1.59 \\
3.84 \\
16.7 \\
29.9 \\
100\end{array}$ \\
\hline
\end{tabular}

s Under columns headed computed are given mass spectra of $\mathrm{C}_{8} \mathrm{H}_{7} \mathrm{D}, \mathrm{C}_{8} \mathrm{H}_{6} \mathrm{D}_{2}$, and $\mathrm{C}_{8} \mathrm{H}_{5} \mathrm{D}_{3}$ computed from $\mathrm{C}_{8} \mathrm{H}_{8}$ assuming a random distribution of $d$ atoms. 
TABLE 2. Computation of mass spectrum of $\mathrm{C}_{8} \mathrm{H}_{7} \mathrm{D}$ for random distribution of $D$ in fragment ions of styrene a

\begin{tabular}{|c|c|c|}
\hline$m / e$ & Ions & $\begin{array}{l}\text { Intensity from } \\
\mathrm{C}_{8} \mathrm{H}_{8} \text { spectrum }\end{array}$ \\
\hline $\begin{array}{l}105 \\
104 \\
103 \\
102 \\
101\end{array}$ & $\begin{array}{l}\mathrm{C}_{8} \mathrm{H}_{7} \mathrm{D} \\
\mathrm{C}_{8} \mathrm{H}_{6} \mathrm{D} \\
\mathrm{C}_{8} \mathrm{H}_{5} \mathrm{D}+\mathrm{C}_{8} \mathrm{H}_{7} \\
\mathrm{C}_{8} \mathrm{H}_{4} \mathrm{D}+\mathrm{C}_{8} \mathrm{H}_{6} \\
\mathrm{C}_{8} \mathrm{H}_{3} \mathrm{D}+\mathrm{C}_{8} \mathrm{H}_{5}\end{array}$ & $\begin{array}{c}(104) \\
7 / 8(103) \\
3 / 4(102)+1 / 8(103) \\
5 / 8(101)+1 / 4(102) \\
1 / 2(100)+3 / 8(101)\end{array}$ \\
\hline $\begin{array}{r}100 \\
99 \\
98 \\
97\end{array}$ & $\begin{array}{r}\mathrm{C}_{8} \mathrm{H}_{2} \mathrm{D}+\mathrm{C}_{8} \mathrm{H}_{4} \\
\mathrm{C}_{8} \mathrm{HD}+\mathrm{C}_{8} \mathrm{H}_{3} \\
\mathrm{C}_{8} \mathrm{D}+\mathrm{C}_{8} \mathrm{H}_{2} \\
\mathrm{C}_{8} \mathrm{H}\end{array}$ & $\begin{array}{c}3 / 8(99)+1 / 2(100) \\
1 / 4(98)+5 / 8(99) \\
1 / 8(97)+3 / 4(98) \\
7 / 8(97)\end{array}$ \\
\hline
\end{tabular}

s Numbers in parentheses denote intensity of designated ion in $\mathrm{C}_{8} \mathrm{H}_{8}$ spectrum

omitted. In this mass range the ions of even molecular weight which give integral half mass numbers are masked by singly charged ion peaks. The half integer peaks of the three monodeuterostyrenes are much alike and table 3 gives the mean values of these.

Since $\mathrm{C}_{8} \mathrm{H}_{8}$ has an even molecular weight while $\mathrm{C}_{8} \mathrm{H}_{7} \mathrm{D}$ has an odd molecular weight the half integer peaks of the two spectra in a sense complement each other. On the assumption that there is a random distribution of $\mathrm{D}$ in the fragment ions, the integral mass peaks in the two spectra can be computed from the observed half integer peaks using the relations of table 2. These computed values are given in parentheses in table 3 . From the complete spectrum of $\mathrm{C}_{8} \mathrm{H}_{8}{ }^{++}$the complete spectra of $\mathrm{C}_{8} \mathrm{H}_{6} \mathrm{D}_{2}{ }^{++}$and $\mathrm{C}_{8} \mathrm{H}_{5} \mathrm{D}_{3}{ }^{++}$can be computed. The computed half integer peaks are in general in very good agreement with the observed peaks and this justifies the assumptions made in computing the $\mathrm{C}_{8} \mathrm{H}_{8}{ }^{++}$spectrum. The intensity distribution in this spectrum is quite unusual. Commonly in aromatic compounds the doubly-charged molecule ion is the most abundant of the doubly charged ions.

TABLE 3. Doubly charged ions of styrenes ${ }^{a}$

\begin{tabular}{|c|c|c|c|c|}
\hline$m / e$ & $\mathrm{C}_{8} \mathrm{H}_{8}$ & $\begin{array}{l}\mathrm{C}_{8} \mathrm{H}_{7} \mathrm{D} \\
(\text { mean) }\end{array}$ & $\mathrm{C}_{8} \mathrm{H}_{6} \mathrm{D}_{2}$ & $\mathrm{C}_{8} \mathrm{H}_{5} \mathrm{D}_{3}$ \\
\hline $\begin{array}{l}48.5 \\
49 \\
49.5 \\
50 \\
50.5 \\
51 \\
51.5 \\
52 \\
52.5 \\
53 \\
53.5\end{array}$ & $\begin{array}{c}0.04 \\
(0.44) \\
0.30 \\
(0.64) \\
0.13 \\
(7.55) \\
0.27 \\
(2.88) \\
--.- \\
-.--\end{array}$ & $\begin{array}{c}0.02 \\
(0.33) \\
0.30 \\
(0.43) \\
0.37 \\
(1.97) \\
5.71 \\
(0.24) \\
2.88 \\
-\end{array}$ & $\begin{array}{l}0.02 \\
(0.25) \\
0.29(0.30) \\
(0.32) \\
0.37(0.41) \\
(0.48) \\
4.12(3.3) \\
(4.12) \\
0.21(0.20) \\
(2.88)\end{array}$ & $\begin{array}{l}0.01 \\
(0.17) \\
0.24(0.28) \\
(0.26) \\
0.30(0.35) \\
(0.32) \\
1.04(0.93) \\
(4.05) \\
2.87(2.81) \\
(0.17) \\
3.00\end{array}$ \\
\hline
\end{tabular}

a Values in parentheses have been computed on the assumption that there is a random distribution of $H$ and $D$ in the fragment ions.

In the $\mathrm{C}_{8} \mathrm{H}_{8}$ spectrum a sharply defined peak at 34.7 mass units of relative intensity 0.01 percent is a triply charged molecule ion. The corresponding peaks at $35.0,35.3$, and 35.7 are found in the spectra of $\mathrm{C}_{8} \mathrm{H}_{7} \mathrm{D}, \mathrm{C}_{8} \mathrm{H}_{6} \mathrm{D}_{2}$, and $\mathrm{C}_{8} \mathrm{H}_{5} \mathrm{D}_{3}$. These ions have not been reported before.

\subsection{Metastable Transition Peaks}

Mass spectra of the deuterostyrenes were recorded with the metastable suppressor voltage off to detect metastable transition peaks. In the $\mathrm{C}_{8} \mathrm{H}_{8}$ spectrum there is a conspicuous broad peak at apparent mass 58.5 which comes from the delayed transition

$$
104^{+} \longrightarrow 78^{+}+26
$$

of relative intensity 0.07 percent. This peak has a broad flat maximum and the "half width" (width between points of ordinate half the maximum value) is 2.1 mass units. The corresponding peaks in the three $\mathrm{C}_{8} \mathrm{H}_{7} \mathrm{D}$ molecules have a "half width" of about 2.5 mass units and the midpoint is about 59.1. This is the unresolved effect of two transitions with $\mathrm{C}_{8} \mathrm{H}_{7} \mathrm{D}^{+}$losing $\mathrm{C}_{2} \mathrm{H}_{2}$ or $\mathrm{C}_{2} \mathrm{HD}$ to give $\mathrm{C}_{6} \mathrm{H}_{5} \mathrm{D}^{+}$and $\mathrm{C}_{6} \mathrm{H}_{6}{ }^{+}$. The apparent masses are 59.4 and 58.0.

The dideuterostyrene has a peak of "half width" 3.5 mass units with the midpoint near 59.6. This is the superposed effect of three peaks at $60.4,58.8$, and 57.4 mass units. The trideuterostyrene has a peak of "half width" 3.2 mass units with the midpoint near 60.1. It is the unresolved effect of three peaks of apparent masses $61.3,59.8$, and 58.3 .

Another metastable transition, conspicuous in these spectra, comes from the loss of one $\mathrm{H}$ atom from the molecule ion. In the $\mathrm{C}_{8} \mathrm{H}_{8}$ spectrum this gives a broadened 102 peak from $104^{+} \longrightarrow 103^{+}+1$. This is seen best when the metastable suppressor is used, for the retarding field is not sufficient to stop an ion differing by only one percent from the kinetic energy of the $102^{+}$ion. With the suppressor on there is a distinct shoulder on the high mass side of the 102 peak near the top of the broader metastable peak. The relative intensity is 0.7 percent. The deuterostyrenes show the same breaks on the corresponding peaks 103,104 , and 105 .

In the $\mathrm{C}_{8} \mathrm{H}_{8}$ spectrum reported in the API catalog serial no. 359 [4] the 58.5 peak has nearly 10 times the relative intensity observed here. Another transition of much lower intensity at 33.8 which was not seen in this work was ascribed to the transition

$$
77^{+} \longrightarrow 51^{+}+26 \text {. }
$$

The differences in measured intensity are ascribed to characteristics of the type 102 and type 103 mass analysers used in the early work and in this research.

\section{Discussion}

The data of table 1 indicate that there is a roughly random distribution of deuterium atoms in the mass spectra of the deuterostyrenes. The agreement is far from exact but the results are in marked contrast to the pattern that would result from simple fragmentation of styrene. Thus $\mathrm{C}_{6} \mathrm{H}_{6}{ }^{+}$is one of the more abundant ions and this suggests that the phenyl ring remains intact and that the alpha hydrogen moves to the ring when $\mathrm{C}_{2} \mathrm{H}_{2}$ is removed from the 
molecule. If this were true $\beta$ - $d$-styrene would give $\mathrm{C}_{6} \mathrm{H}_{6}{ }^{+}$while $p$ - $d$-styrene and $\alpha$ - $d$-styrene would give $\mathrm{C}_{6} \mathrm{H}_{5} \mathrm{D}^{+}$. This is not the case, for the 79 peak is large in all three spectra, although both $\alpha$ and $\beta$ deuterostyrene give a 79 peak somewhat smaller than the computed abundance for random distribution.

In the metastable transitions giving $\mathrm{C}_{6} \mathrm{H}_{6}{ }^{+}$and $\mathrm{C}_{6} \mathrm{H}_{5} \mathrm{D}^{+}$from $\mathrm{C}_{8} \mathrm{H}_{7} \mathrm{D}^{+}$the two peaks are not resolved but the three monodeuterostyrenes give a similar distribution of intensity in the broad peaks showing a similar distribution of deuterium atoms in the fragment ions. If $\beta$-deuterostyrene and $\beta, \beta$-dideuterostyrene dissociated by losing $\mathrm{C}_{2} \mathrm{HD}$ and $\mathrm{C}_{2} \mathrm{D}_{2}$, respectively, then the apparent masses would be 58.0 and 57.4 as compared with 58.5 for $\mathrm{C}_{8} \mathrm{H}_{8}{ }^{+}$. The observed values are 59.1 and 59.6 .

The fragmentation of alkylaromatics has been studied rather carefully by Meyerson and Rylander $[2,5,6]$ using spectra of isotopically labeled molecules and considerations of energetics of ion formation in their study. They suggest that formation of a tropylium ion (cyclic $\mathrm{C}_{7} \mathrm{H}_{7}{ }^{+}$) is an intermediate step in the fragmentation.

This suggests that formation of a cyclooctatetraene ion may be an intermediate step in the fragmentation of styrene. The spectrum of clyclooctatetraene has been published in the API catalog [7]. The intensity of all the fragment ions is roughly twice that observed in styrene but there is a close parallelism in the relative intensities. Metastable transition peaks at $102,58.5$, and 33.8 are the same delayed transitions that are found in styrene. A fourth peak is reported at 34.7 but this is probably the triply charged ion, not a metastable transition. It is interesting that in both mass spectra $\mathrm{C}_{6} \mathrm{H}_{6}+$ is one of the most abundant fragment ions $(82 \%$ in the cyclic and $38 \%$ in styrene). In the case of cyclooctatetraene the fragment ion $\mathrm{C}_{6} \mathrm{H}_{6}{ }^{+}$is probably not a benzene ion and it follows that $\mathrm{C}_{6} \mathrm{H}_{6}+$ of styrene is not necessarily a benzene ring.

If styrene ions form an octatetraene ring and then dissociate, the distribution of $\mathrm{D}$ should be completely random. This is not the case, although the random distribution gives a good approximation to the observed distribution. There may be alternative modes of dissociation into fragment ions. This would not be surprising but it suggests that it would be of some interest to study the distribution of D atoms at low voltage near the threshold for appearance of fragment ions.

The authors thank Leo A. Wall of the Polymer Structure Section for making available to us the samples of the five deuterostyrenes.

\section{References}

[1] Am. Petrol. Inst., Catalog of mass spectral data serial numbers 430, 431, 837, and 838 .

[2] P. N. Rylander, S. Meyerson, and H. M. Grubb, J. Am. Chem. Soc. $\mathbf{7 9}, 842$ (1957)

[3] L. A. Wall and D. W. Brown, J. Phys. Chem. 61, 129 (1957)

[4] Am. Petrol. Inst., Catalog of mass spectral data serial numbers 359 and 1289 to 1293.

[5] S. Meyerson and P. N. Rylander, J. Chem. Phys. 27, 901 (1957).

[6] P. N. Rylander and S. Meyerson, J. Chem. Phys. 27, 1116 (1957).

[7] Am. Petrol. Inst., Catalog of mass spectral data serial number 690 .

Washington, October 13, 1958. 